\title{
Interrogating Practitioner Tensions for Raising Citizen Voice with Participatory Video in International Development
}

\author{
Tamara Plush
}

\begin{abstract}
Within international development, strengthening the voice of citizens living in poverty is recognised as vital to reducing inequity. In support of such endeavors, participatory video $(\mathrm{PV})$ is an increasingly utilised communicative method that can stimulate community engagement and amplify the voice of groups often excluded from decision-making spaces. However, implementing PV processes specifically within an international development context is an immensely complex proposal. Practitioners must take into consideration the different ways institutions may understand the use of participatory video for raising citizen voice; and how therefore the practice may be influenced, co-opted or even devalued by these institutional assumptions. To this end, this article interrogates how global PV practitioners express tension in their work. Analysis of their descriptions suggests six influential views on PV practice with the potential to diminish the value of voice from the margins.
\end{abstract}

Keywords: participatory video, international development, citizen, voice, practice

\section{Introduction}

In the field of communication for development and social change, reducing poverty and inequity requires practitioners to adopt approaches that prioritise transformative politics, equitable power relations, human rights and social justice (Dutta 2011: 7, 8; Servaes 2013: 369; Wilkins et al. 2014: 138). These are methods that support people on the margins in using their own agency and voice to engage in the "decisions and deliverables affecting their lives" (Dutta 2011: 3; Gaventa and Barrett 2010: 4; Servaes and Liu 2007: 2). Practitioners who work in an international development context have been especially keen to adopt participatory video (PV) processes that can strengthen, amplify and legitimise the voice of people living in poverty (Khamis et al. 2009: 130; Wheeler 2011: 55).

Participatory video is different than documentary filmmaking and even advocacy or activism video; where external filmmakers work closely with community members to construct a film about their situation for education or mobilisation purposes (Gregory and Gábriel 2005: 11). While it may have similar goals for experiential learning and collective action, the PV method specifically prioritises iterative processes of filmmaking, viewings and dialogue to support the people least heard in societies to represent them- 
selves privately and publically (Braden 1999: 1; Mitchell et al. 2012: 1; Plush 2012: 77). PV processes often aim to create new opportunities for awareness-raising and dialogue between the local filmmakers and policy-makers (Bery 2003: 161; Wheeler 2009: 10; White 2003: 9). This is especially meaningful for citizens who may have limited access to such platforms. With its potential for projecting unseen perspectives (Mitchell et al. 2012: 1; Wheeler 2011: 55), participatory video is often embedded into development programmes specifically to raise the voice of excluded or marginalised populations (Dudley 2003: 286; Plush 2009: 119).

Tensions, however, can arise for PV practitioners when working in international development contexts due to organisational, political and relational interests that often interact in contradictory ways in policy and practice (Gumucio-Dagron 2008: 229; Lennie and Tacchi 2013: 6; Waisbord 2008: 508). Because of this, it is vital for practitioners to consider particular expectations for participatory video that institutions (non-government or organisations, research bodies, government departments or funding agencies) may hold; and how practice may be influenced, co-opted or even devalued by these institutional assumptions. Such considerations are imperative if PV praxis is to live up to its potential for enabling citizen voice so it can be respected and sustained rather than undermined or denied (Couldry 2010: 1-2; Tacchi 2010: 7).

\section{PV Practitioners' Tensions in an International Development Context}

The research base for this article comes through a qualitative study that explored the cognitive representations and lived experiences of global PV practitioners ${ }^{1}$ who have used PV to raise citizen voice in international development contexts. ${ }^{2}$ The 25 participants are contemporary practitioners who have influenced the PV discourse through authoring books and academic articles on PV, developing PV toolkits or how-to manuals, leading PV workshops in multiple countries, creating instructional videos for internet distribution, speaking about PV at global conferences and/or engaging in communities of practice. Four have 1-3 years' experience; 10 have 4-7 years; seven have 8-15 years; and four have more than 16 years' experience. ${ }^{3}$ During the semi-structured interviews, practitioners related their experiences to more than $650 \mathrm{PV}$ projects; ${ }^{4}$ with approximately 250 of those designed specifically to raise the voice of excluded groups in an international development context. The interviews also incorporated a visual method process where practitioners illustrated their visions for idealised practice in storyboard form. ${ }^{5}$ The storyboards helped participants to conceptualise their ideals and were used as a guidepost during the interviews to probe deeper cognitions of PV and raising voice (Labacher et al. 2012: 151).

To locate institutional influences on PV praxis, the research analysed the tensions practitioners described in their practice. Through this process, the research identified more than 650 formulated meanings; and clustered them into 20 overall themes. The themes were counted and analysed to identify two key areas of influence-purpose and experience-with six institutional views of participatory video in international development classified as agenda-driven, output-focused, voice as opportunity, apolitical participation, innocuous and quick-to-learn and sustainable (see Figure 1.1). These views, individually and collectively, do not represent an absolute or normative understanding of PV praxis by all organisations. Rather, they represent the most influential 
Figure 1.1

\section{Institutional Views of Participatory Video}

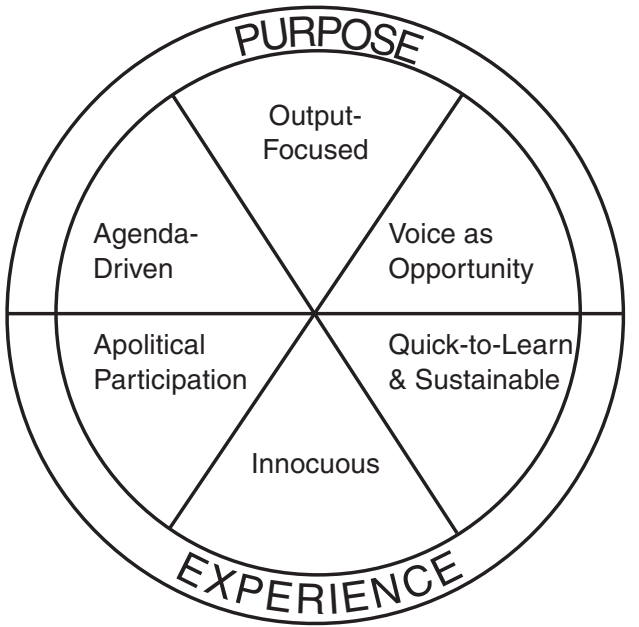

institutional views that the practitioners in the study identified as having the greatest potential for diminishing participatory video's intention of raising citizen voice. They are the key views the 25 practitioners described as having to consistently respond to and negotiate with non-government organisations, research institutions, government departments or funding agencies. As such, the views are not necessarily universal. However, based on the extensive experience of the practitioners in the study, the views necessitate mindful consideration by a wider field of PV practitioners and organisations who work in development contexts on efforts that aim to raise the voice of people who most need to be heard.

\section{Purpose: The First Area of Institutional Influence on PV}

In the study, a main concern for the practitioners is that institutions often fail to comprehend or embrace the underlying principles for why they might use participatory video for development. Rather, they often instigate the method through celebratory notions of PV as "sexy and adventurous," "super cool," "something new," "a really interesting tool," "innovative" or "authentic" (Katulpa, 16+ years; Nikita, 4-7 years; Quinn, 7-15 years; Juno, 4-7 years; Alex, 1-3 years). ${ }^{6}$ By initiating PV projects through an uncritical lens, the practitioners worried that PV could become "trivialised," "a buzzword" or "anecdotal" as has happened to other participatory approaches in development (Toni, 8-15 years; Nikita ; Shane, 4-7 years). They expressed concern that this will lead the practice away from "a journey towards understanding, dialogue, communication and action for change" (Jessie, 16+ years). Such tensions are exemplified through three key institutional views that the 25 practitioners said arise from influences on the purpose of using PV: 1) PV operates through the agenda of the funding body or organisation where it is embedded; 2) PV is a filmmaking process that creates a video output that can be used for organisational gain; and 3) PV primarily offers the opportunity for often excluded groups to infuse their voice into mainstream spaces. 


\section{View 1: PV is Agenda-Driven}

In this first institutional view of participatory video practice, named here as an agendadriven view, practitioners expressed concern that organisational expectations, agendas and operational procedures can constrain the "creative," "flexible and responsive," "slow kind of empowerment" processes needed for raising voice with PV (Addison, 4-7 years; Tyler, 8-15 years; Katulpa). They specifically pointed to a rise in the development sector of results-based management procedures and linear planning processes that prioritise short-term outcomes over long-term impacts. They worried that these operational structures might systemically negate "all this talk about hearing the voices of the people; about empowerment" (Katulpa). This can happen when institutions require citizen voice to fit "within the parameters and terms they dictate" (Quinn). Such terms are often set through linear planning tools, like log frames, that can contradict the "creative, action-based" ways communities operate (Nic, 8-15 years). As the practitioner further explained, "log frames are not good at coping or placing priority on non-quantifiable indicators such as the level of ownership of the work. So these things tend to be dropped off." Ownership, in other words, refers not only to local control of the video content, but in how the participants want to use PV to influence decisions that impact their lives.

Practitioners explained that this growing emphasis on time-bound, pre-defined outcomes creates an environment where it is easier for development organisations to embrace what they labelled as "formulaic," "technocratic," "machine-based" or "simplistic" approaches to PV (Jessie; Kai, 4-7 years; Addison; Tyler). This is where step-by-step approaches are promoted regardless of the local context, culture, political economy, power dynamics, religion or gender considerations. Such views can reinforce organisational perceptions of PV practitioners" as "outside experts providing technical or instrumental training in production skills" (Jessie). Practitioners also worried that prescriptive approaches can impact how participants feel their voice is valued in the PV process: "I don't think people respond to formulas as they know that you are going by the recipe rather than actually responding to them and who they are" (Tyler). Such tensions fueled practitioner concerns that standardised PV approaches can ignore social and political complexity:

\footnotetext{
When you are talking about social change, it's not a linear process. It's not like you make an advance and there's no backtracking. We know that policies don't get enacted in the same way they were intended a lot of the time. We know that the kinds of changes that need to happen and the kind of level of which that change needs to happen is not very connected to the policies that are available. There are a lot of questions about that. And if you are using PV in an instrumental way, you are merely going to reinforce all of those powers. You're not necessarily going to challenge them. You are still within a system - that development system - unless you can find a way to challenge it (Devon, 8-15 years).
}

Even when PV has been designed to be more responsive to community concerns, a few practitioners described situations where results-based agendas have diminished potential for sustained citizen voice. A practitioner working within a large NGO, illustrated this through a story about a PV project embedded in a development programme in rural Africa focused on unpaid care. ${ }^{8}$ In this project, a women's group used the PV method to 
highlight concerns related to a local waste dump. While they successfully engaged with decision-makers at a municipality meeting using the visual evidence they had gathered, a greater challenge came in being able to address this issue over the long-term. One problem was that the women's chosen topic did not fit within the programme's predesigned framework. As a consequence, the in-country programming staff ended up being so focused on "reporting and delivering a programme rather than achieving change within the community [that] what the women were trying to achieve got lost" (Alex).

\section{View 2: Output-Focused}

In this second institutional view, the output-focused view of practice, practitioners worried that institutions primarily see PV as a communication or public relations activity that results in a video output; rather than a method for development that incorporates video. This is where participatory video is desired for "self-promotion," "another form of report," to "beef up a PowerPoint presentation" or to get video clips for the organisation's website or social media site. (Toni; Kai; Ash, 4-7 years). In such cases, one practitioner explained that organisations are rarely thinking, "“I I want to deeply empower and enable a group. I want to create a place for people where they can reflect back on their experiences;" and for that sort of personal development and transformation" (Quinn). Such views can be accentuated by an NGO sector that often sees PV practitioners as "semi-documentary makers, with a bit of community thrown in" (Katulpa). When this happens, the core value for using PV to raise the voice of citizens can be lost:

“Citizens" means some sort of social organizing. And without that, I don't think you can have citizens' voice. To me, citizens' voice means social organisation, which then - in the final stages - has a voice. When I say final stages, there is that to-and-fro where you can actually use media as a way of assisting the process of social organising. So doing things together, people organise. That's the process as opposed to the output (Nic).

A focus on PV as output can also lead to processes that inadvertently exploit community members: "It's not intended to be as such, but it ends up being cheap labor to make communicative documents for people who have the opportunity to use them and show them" (Toni). This can create scenarios where the product itself has higher value than the people and process behind it, as illustrated by a call for deeper reflexivity in praxis:

It is important that we look at how that colonisation of local voices happens within NGOs. So much of what you can see - even in what are called PV tapes - is of a genre where the refugee kid provokes the response, "How sweet!" Or the peasant woman operating the camera provokes exclamations, "Amazing!" All of which produces what Deleuze would call schizo-cultural distance (Katulpa).

A few practitioners observed that the output-focused view can be strong when PV is aligned with organisations' communication departments as they traditionally focus on developing products and campaigns. This can be problematic since communication departments do not often have the mandate for "really reaching the communities and hearing their voice; and helping them to communicate" (Zhenya, 8-15 years). 


\section{View 3: Voice as Opportunity}

In the third view of practice, named the voice as opportunity view, the practitioners discussed different ways participatory video is perceived as a method to raise citizen voice within international development. On one hand, all practitioners supported the institutional view that PV offers excluded groups a "chance for them to get their messages, their stories, out to the world" (Seri, 1-3 years). On the other hand, about half expressed concern that this action alone often constitutes the totality of how institutions understand raising citizen voice; even within development organisations promoting social change. This can lead to a disconnect between the value organisations place on widely disseminating community voice for global outreach and advocacy verses the importance of local impact for the people who made films through PV processes, as one practitioner explained:

As soon as you start to set an international or outside target, it can just be orientated about really just getting their voice and their thoughts. And there you go. The action kind of happens out there. It may kind of filter back. There may or may not be impacts directly felt by the target community. It is often how it tends to be seen in the development world (Zhenya).

Many related this to a naive view within institutions that creating opportunities for voice alone will inherently lead to social change or justice. As a consequence, PV project budgets often only include resources to make and publically disseminate the community film or films. Funding for wider efforts that might ensure the participants' voice has the potential to be recognised and responded to in the longer-term is often not considered. Practitioners explained that naive expectations often happen when participatory video is viewed as a means to give voice - like a gift or a commodity. This is where the opportunity for people living in poverty to put their opinions on film becomes the outcome; rather than efforts that help address the cultural, political and economic structures that have marginalised and continue to marginalise participants' voice.

Examples of this in practice were shared by a few practitioners who discussed projects where NGO staff members, local government officials or community leaders were taught filmmaking skills in one to two days. They then used these skills to gather a wide range of opinions on the selected topic; often in short, community visits (i.e. providing people with opportunities for voice). While such practices can be valuable for infusing rarely heard concerns into wider debates, many worried that this in-and-out approach offers little time for people to "have a choice as to how they want to represent themselves" publically (Katulpa). Time is also limited for deeply exploring the issues being discussed. This was illustrated by a practitioner who described a PV process where village-level involvement typically included only a few hours in a community. In this time, people gathered to share their opinions on a pre-determined topic:

In theory, it provides an opportunity for the people on the ground, community members in some of the poorest places, to say what are their needs; what are some of the issues. But on the flip slide, if you watch some of the videos we have, it's basically a wish list of "these are the things we want" (Gustl, 1-3 years).

In a quest for wide geographical reach, the time-bound approach can also discount power dynamics inherent not only in who speaks, but in who holds the camera. This 
was illustrated through a technical description about how newly trained facilitators used a focus-group approach (with pre-determined questions) in an Africa-based PV project designed to capture multiple voices:

Let's say that they have a discussion of 45-60 minutes. After the 60 minutes, they interview the people who want to say something; or the most interesting people; or who the group feels are the right representatives to share their hopes and dreams. It is also easy for the editing if you first do a discussion of 45 to 60 minutes, and after that you do some short interviews of 3-4 minutes each with the four different questions (Kendall, 4-7 years).

This example highlights a concern by other practitioners that approaches focused mainly on providing opportunities for voice could unintentionally reinforce the status quo by supporting those with the greatest confidence or loudest voice. Thus, rather than using PV for "changing the power dynamics between people living in poverty and decisionmakers" (Jessie), the process can give a microphone to those who already have power in the community.

That said, in the African project mentioned above, the facilitating practitioner also described how participants in the final videos felt when viewing their concerns on film alongside more powerful people in the community:

It gives them a feeling that they are recognised. And if they express that, it is already a big step in raising citizen voice. Because they feel recognised and feel listened to; they feel seen; they get a position in the community... Of course, the hierarchy remains; and that's probably in the culture. But at least people get the opportunity to share and speak up equally (Kendall).

This observation exemplifies how valuable it can be for people to have their voice recognised in public policy spaces. However, it likewise shows that having the opportunity for voice alone may not be enough to shift entrenched power relations. As the practitioner explained when talking about the focus-group approach to gathering opinions, "the disadvantage is that some of the marginalised people, they may not speak up in this train-the-trainer model I am using." This echoes the concern another practitioner described when talking about how short-form notions for raising citizen voice can miss its deeper value:

Fine; go and do something in three days, but don't call it voice. Call it something else... That's data collection. The data is people speaking themselves about the film on a topic; and they learn some technical skills. But, that's not empowerment. That's not what I define as voice. Voice is much more. It's a personal as well as a political process. And so in that sense, it's quite profound. It's very easy to skim along the surface of these things and that often happens (Devon).

\section{Experience: The Second Area of Institutional Influence on PV}

The above section described three institutional views that the practitioners in the study said organizations' often hold concerning the purpose or reason why they might use participatory video for development. Alongside these is a second area of influence, which focuses on three additional views that the practitioners identified as affecting the experi- 
ence of developing PV. In this area, the practitioners expressed tension about the "relationships to power" operating, the tendency for organisations to "depoliticise the process" and "naive politics" concerning how people learn (Katulpa; Nikita; Jessie). The practitioners explained that these views impacted the experience of how they were able to implement their principled ideals for PV practice. Through such discussions, the practitioners suggested three views as key points of tension in their work: 1) PV is primarily driven through apolitical activities that community members engage in; 2) PV is innocuous in that any harm that might occur through PV processes is limited; and 3) PV processes can be mastered through quick-to-learn facilitated sessions and in sustainable ways.

\section{View 4: Apolitical Participation}

In the fourth view, named the apolitical participation view, the practitioners worried that institutions often fail to prioritise or value using participatory video for the "political underlying notions of citizen voice" vital for transformative social change (Juno). Practitioners explained that PV needs to go beyond "light bulbs over the people's heads" where participants share their opinions on film and expect others to do something about it (Alex). Instead, it requires PV processes that strengthen participants' long-term capacity to "represent their own case; where they can make their own demands without depending on some outside agency to do it" (Alex). Promoting this approach, the practitioners explained, is difficult as many development institutions are not willing to take political risks. This is despite PV being inherently political, as one practitioner explained when discussing its use for social justice: "This is not neutral what we are doing. It has a very political, with a small-p nature" (Devon). A practitioner who often works with disenfranchised youth agreed:

If we are doing a project and people are being listened to and they are able to engage
with their wider society; and they're developing a voice and their thoughts; and
they are addressing us in the first instance, or a slightly wider audience, that's a
political act. For some of the groups we work with, they just don't expect anyone
to listen to them or take notice of them... But in terms of whether that's embedded
in the funding or whether that's what other people want to get from it... I find
that a lot of the groups I work with, we don't talk about that (Sal, 16+ years).

Practitioners attributed the apolitical view to development organisations being, as one practitioner explained, "quite invested in their professional identities" in how they are viewed or in what they can say (Devon). This can stem from government-to-government agreements that often dictate NGO policies and practices in developing countries. In such an environment, PV praxis ends up focused on "raising voice" without "talking about hearing voices;" especially those voices that "don't fit the agenda" (Katulpa). This is where the PV process becomes a top-down activity where decision-makers can "tick boxes and say, "Well, we've consulted; we've heard people." Then that's it. Nothing ever changes" (Jessie). One practitioner further expressed concern that many PV practitioners are unaware of the impact of NGO influences on citizen voice:

One of the problems about PV practitioners being very closely aligned to NGOs is that it can lead to the colonising of local voices in support of what are actually NGO agendas: programmes, policies and fundraising. It is the unspoken collu- 
sion, or maybe it is the unconscious collusion that takes hold of professional bodies and institutions as they struggle with their own internal management and financial matters (Katulpa).

A practitioner who often uses PV for monitoring and evaluation illustrated this in explaining how institutions can mitigate political engagement through PV project design and funding. $\mathrm{S} / \mathrm{he}^{9}$ said that in the majority of projects $\mathrm{s} / \mathrm{he}$ 's facilitated that were designed by Western NGOs, "the part where the video is shown to the policy-makers is not part of the participatory video process" (Kai). In other words, participants were structurally denied opportunities to connect their voice with the people they believe can best respond to their concerns. Similarly another practitioner told a story about working with rural African farmers on a PV project funded by a large corporation. PV processes were used to gather farmer opinions about new practices introduced by the organisation. While the collaborative filmmaking aspect went smoothly, the company worried that a community showing of the footage might insight "a revolution kind of thing" (Mel, 4-7 years). In the end, the practitioner was able to negotiate the value of the local screening. However, after s/he left the village, the corporation did not fund additional community usage of the film itself. It also failed to promote the film publically after it was shown at a conference; despite the farmers' interest in doing so. Reflecting on such cases, practitioners pointed out that the political roots of participatory development approaches are often misinterpreted:

There are a lot of organisations who think they know what participatory methods are and have dabbled with them; and are applying them, but have not really gone through the shift - the internal shift; the attitude shift that needs to come clear to make it really authentic. And so in terms of power and who is holding that power, and in design and implementation, and organisation and projects, they haven't shared that fully (Zhenya).

In talking about the value of the "more activist and the more civic-driven processes" that can raise citizen voice, a practitioner offered this observation:

What I see is that quite often the word participation is being stimulated by a lot of actors, with really good results. But quite often within boundaries of what professional organisations deem interesting or necessary. And there seems to be a very wide gap between citizen activism and structural participation in organisations (Juno).

\section{View 5: Innocuous}

In the fifth view, the innocuous view of practice, practitioners explained that organisations often regard participatory video as an innocuous approach. In many cases, they failed to consider that PV processes can "go wrong," "be threatening or risky," "endanger the safety of people," "result in repressing voice," "position people in a worse way," "exclude the most excluded," "cause conflict within a group" or "unwittingly add to a sensitive situation" (Morgan, 4-7 years; Kendall; Addison; Jessie; Cass, 4-7 years; Gustl). In discussions about potential harm, practitioners talked about how PV can reinforce unequal power relations, increase vulnerable situations or even disempower participants. 
You think you are teaching people to run a process, but people get power through having control of the kit. So you end up rather than spreading skills and breaking down power dynamics, you end up supporting the existing power dynamics within a community (Jessie).

The practitioners said local power can be most visible during participant selection processes that determine who will receive the PV training and equipment. Reasons for why certain community members become participants included the tendency for those with the most confidence to volunteer; people in power wanting their relatives or friends to gain from any skills or resources offered in the PV activities; or cultural norms that favour particular individuals or groups over others, such as related to gender or caste. A practitioner working in Asia explained the difficulty in breaking down power inequities as an outsider:

I had the experience where we wanted to integrate Dalits into the group. But in the end it didn't work out. They came to the training. I don't know if they were accepted by others or not. After the training other participants told us that the Dalit participants are not serious and are not interested to work towards making a film. But it's very difficult for me to know the reality... The field assistant who lives there has helped us to form these groups knows this community very well. But I don't really know if what she says is the reality. I have to accept that (Sasha, 1-3 years).

The practitioners described potentially negative consequences for participants both while creating their films and having them publically shown. They worried for people who describe deeply personal situations; criticise power structures that foster inequity; provide evidence of undelivered government services; or expose human rights atrocities. As an illustration of the tensions, a practitioner who often uses PV for child rights, said s/he sometimes sees child-led participatory videos and wonders, "Is this really the interest of the child? If they made this, isn't that child going to get in trouble? How is follow-up being organised? Have they at all thought about this? Is ethics even a part of the process" (Juno)? In response, practitioners said greater attention is needed in PV praxis for assessment and planning of "potential risks" to ensure participants "are being cared for or being supported" after they share their stories in private and public ways (Nikita; Ash).

Another worry by practitioners was about the potential for harm when participants are not part of how their voice is being used; especially for populations who are already quite marginalised. This was illustrated by a practitioner who often works with refugee youth:

If you are asking someone to make media or you are engaging them in a media process and they are not engaged in the next stage in the civic action around it... then you have disempowered them. You've patronised that work rather than actually making them part of that process of that response (Misha, 16+ years).

\section{View 6: Quick-to-Learn and Sustainable}

In the sixth institutional view of practice, named as the quick-to-learn and sustainable view, the practitioners discussed how participatory video processes require multiple skills related to facilitation, community development, research and technical film- 
making. Because of this, many worried when organisations assumed that PV can be quickly learned, replicated and sustained in poor communities; often without adequate or on-going support. Practitioners explained that tensions arise when institutions expect them, in short timeframes, to both implement empowering processes that can raise the voice of participants and train those participants to replicate the same processes after they leave. While some practitioners were able to work long-term in developing countries to achieve this outcome, the majority facilitated PV projects through short timelines ranging from five days to three weeks. Only a few practitioners described being able to revisit communities after the initial PV training to support on-going participant learning.

What this means is that time is often limited for participants to not only acquire video production skills (such as videography, basic editing, visual language and storytelling); but to also learn the facilitation skills that set PV apart from traditional filmmaking. This is often seen as a contradiction for practice:

It is understood that to learn how to makes films, professional should do long-term college courses; or to become social, community workers or researchers the same. But somehow people in the community are supposed to be able to build skills overnight, even though they are much less well-placed due to life constraints to do so (Jessie).

The practitioner also shared concerns about short-term PV projects where the funding stops after the film or films are made: “There isn't any finance to do what is the more important work. You get the funding to write your how-to manual, but not to ensure that what is done is used appropriately" (Jessie). Practitioners observed that the proliferation of how-to manuals and step-by-step guides can mask the difficulty of training facilitators where "you are creating kind of a super man or woman; because to be a great facilitator, you need many, many skills and attributes. And it's very hard to find that in one human being" (Zhenya). In response, one practitioner promoted a train-thepractitioner approach:

What people really need is a mentoring process... If they decide that they want to run processes, whatever those look like, that they have someone, or more than one someone, who works with them and helps them work through all the issues and is with them along the way as they confront those problems and think about how to deal with them. And that's much more likely for people to then be able to use it. Running people through five-day, train-the-trainer workshops is not going to do it (Devon).

Even when organisations support the need for sufficient training, finding funding can be difficult: "Participatory video is quite an investment. So far as I have seen, not so many projects are budgeting for that; or are not yet ready for that" (Kendall). As well, in locations where PV has continued after initial trainings, practitioners explained that often its underlying principles drop off and traditional filmmaking processes remain. In such cases, decision-making power or the film equipment can be taken over by the most technically savvy people in the group or the most powerful community members. One practitioner explained that this can happen at the organisational level where staff members are trained as PV facilitators but are not "given the space and opportunity to 
do it within their pre-existing work load" (Quinn). And it can happen at the local level where powerful actors co-opt the process. As one example, a practitioner who worked on a year-long PV project in Africa worried that the young people s/he trained now face difficulties in being able to make their own films in their own voice due to a lack of organisational support. In this context, s/he expects that powerful community members will push the youth to more closely align their skills with traditional "income generation" activities such as weddings or that they will be coerced into "filming political campaigns for local politicians, for probably no pay" (River, 8-15 years).

\section{Implications for PV Practice and Citizen Voice}

The two areas explored above - purpose and experience - make explicit six institutional views within international development that the 25 practitioners in the study suggest can subtly devalue or diminish participatory video's potential for raising citizen voice; despite opposing intentions in principle (Couldry 2010: 10). These views relate to institutions' pre-determined agendas, requirements for promotional film outputs, process notions of voice, promotion of apolitical participation, support for PV as an innocuous intervention and expectations for sustainable skills transfer in short timeframes. Despite the tensions they might create for PV praxis, such views are rarely the result of "underhanded, malevolent intentions" (Waisbord 2008: 508). Rather they are responses to operational structures that often make it difficult to adopt participatory communicative approaches. Thus, it is important that the six identified institutional assumptions are recognised and used by PV practitioners as discussion and reflection points for strengthening efforts to raise citizen voice with participatory video.

Consideration of the influential views is especially vital when PV is located in an international development sector that primarily promotes traditional communication paradigms supporting vertical message delivery (Gumucio-Dagron 2009: 453). This is where the participatory aspect of social change communication is regarded as "mere rhetoric, not practiced or implemented in top-down ways" (Lennie and Tacchi 2013: 6). In such a context, it is only when practitioners are able to fully embrace the "complex reality of project application" that participatory video's potential for raising citizen voice can be meaningfully realised (Low et al. 2012: 61; Shaw 2012: 225).

Of course, such action is not straight-forward. It implies a "deliberate process of becoming unsettled about what is normal" (Eyben 2014: 1). This means that PV practitioners working in development need to pause and reflect on how they personally respond to the institutional views suggested in the study. It requires interrogating how their own views might play a parallel, influential role through varying degrees of response from compliance to resistance. Such responses may be related to their own theories on voice and participation, educational background, practical experience, peer influence, ethical approaches to practice and personal values. This should be aided by further academic research into what strategies are needed to reach PV's potential for raising citizen voice in an international development context. Or, more radically, what are the alternatives for participatory video praxis to work alongside dominant development structures in support of "transformative politics and redistributive justice" (Dutta 2011: 2, 8).

Such action supports theoretical arguments that focus the PV discourse away from best-practice debates. It does so by shifting the conversation to the intersection between 
"conditions under which participation is generated or regenerated" and PV practitioner skills, values and agency (High et al. 2012: 45). Pursuit of this knowledge will not only bolster participatory video as viable method for communication for development and social change. It can also, more importantly, strengthen the potential for the voices of excluded groups to meaningfully matter in the persistent struggle to reduce global inequity (Couldry 2010: 7).

\section{Notes}

1. The participants are from Australasia, Europe and the Americas; 75 percent are individuals who have focused solely on development practice; the other 25 percent have used PV as a research for development process.

2. In clarifying raising citizen voice, the research was approached with the understanding that citizenship encompasses people with limited decision-making power being able to challenge those who have more power in relation to their development; be it personal, social or political development. This distinction is important as one of the practitioners in the study works specifically with refugee populations. By looking at citizen voice through a focus on "participation, voice and engagement" rather than a legal status, the research includes the practitioner's interview in the analysis (Gaventa and Barrett 2010).

3. For anonymity in a small field of practitioners, PV experience is capped at 16 years even through individual experience is much higher for certain practitioners. Statistical data is current from the date of the interviews in early 2014.

4. The research allowed the participants to set the parameters of how they define a PV project. For example, one practitioner worked for many years with one group on one "project" but making many films. It was left to their discretion if they would define this as one project, or count each filmmaking activity separately.

5. 18 of the 25 practitioners completed storyboards.

6. For anonymity, practitioners selected pseudonyms. Practitioner quotes list their pseudonym and years of practice; represented by 1-3 years; 4-7 years; 8 -15 years; or 16+ years.

7. Once a practitioner has been identified by their years' experience, they are subsequently referred to only by their pseudonym.

8. Unpaid care relates to care people provide, mostly women, without economic gain. This can be "looking after and educating children, looking after older family members, caring for the sick, preparing food, cleaning, and collecting water and fuel." (see http://interactions.eldis.org/unpaid-care-work/issues/whatunpaid-care. Accessed October 21, 2014).

9. Gender-neutral pronouns are used for practitioner anonymity.

\section{References}

Bery, R. (2003). 'Participatory Video that Empowers', in S. A. White (ed.), Participatory Video: Images that Transform and Empower, Sage, 102-121.

Braden, S. (1999). 'Using video for research and representation: basic human needs and critical pedagogy', Journal of Educational Media, 24 (2), 117-129.

Couldry, N. (2010). Why voice matters: Culture and politics after neoliberalism. London: Sage.

Dudley, M. J. (2003). 'Voice, Visibility, and Transparency: Participatory Video as an Empowerment Tool for Colombian Domestic Workers', Participatory Video: Images that transform and empower, Sage, 286-308.

Dutta, M. J. (2011). Communicating Social Change : Structure, Culture, and Agency. Hoboken: Taylor and Francis.

Eyben, R. (2014). International aid and the making of a better world: reflexive practice. New York, NY: Routledge.

Gaventa, J. and Barrett, G. (2010). So what difference does it make?: Mapping the outcomes of citizen engagement (347) Brighton, UK: Institute of Development Studies at the University of Sussex.

Gregory, S. and Gábriel, P. (2005). Video for change: A guide for advocacy and activism. Ann Arbor, MI: Pluto Press.

Gumucio-Dagron, A. (2008). 'Vertical Minds versus Horizontal Cultures', in Jan Servaes (ed.), Communication for development and social change. New Delhi: Sage, 68-81.

Gumucio-Dagron, A. (2009). 'Playing with Fire: Power, Participation, and Communication for Development', Development in Practice, 19 (4/5), 453-465. 
High, C., et al. (2012). 'Defining Participatory Video from Practice', in E. J. Milne, Claudia Mitchell, and Naydene De Lange (eds.), Handbook of participatory video. Lanham, MD: AltaMira Press, 35-48.

Khamis, M., Plush, T., and Zelaya, C. S. (2009). 'Women's rights in climate change: using video as a tool for empowerment in Nepal', Gender \& Development, 17 (1), 125-135.

Labacher, L., et al. (2012). 'What Can a Visual Researcher Do with a Storyboard?' in Milne, E. J., Mitchell, C., and De Lange N. (eds.), Handbook of participatory video Lanham, MD: AltaMira Press, 149-163.

Lennie, J. and T., J. (2013). Evaluating Communication for Development: A Framework for Social Change. Taylor \& Francis.

Low, B., et al. (2012). '(Re)framing the Scholarship on Participatory Video: From Celebration to Critical Engagement', in Milne, E. J., Mitchell, C., and De Lange N. (eds.), Handbook of participatory video Lanham, MD: AltaMira Press, 49-66.

Mitchell, C., Milne, E. J., and De Lange, N. (2012). 'Introduction', Handbook of participatory video. Lanham, MD: AltaMira Press, 1-15.

Plush, T. (2009). 'Amplifying Children's Voices on Climate Change: The Role of Participatory Video', Participatory Learning and Action, 60, 119-128.

Plush, T. (2012). 'Fostering Social Change through Participatory Video: A Conceptual Framework', in Milne, E. J. Mitchell, C., and De Lange N. (eds.), Handbook of participatory video. Lanham, MD: AltaMira Press, 67-84.

Servaes, J. (2013). Sustainability, participation \& culture in communication: Theory and praxis. Bristol: Intellect.

Servaes, J. and Shuang, L. (2007). Moving targets: Mapping the paths between communication, technology and social change in communities. Penang, Malaysia: Southbound.

Shaw, Jackie (2012). 'Interrogating the Gap between the Ideals and Practice Reality of Participatory Video', in Milne, E. J., Mitchell, C., and De Lange, N. (eds.), Handbook of participatory video. Lanham, MD: AltaMira Press, 225-241.

Tacchi, J. (2010). 'Open content creation: The issues of voice and the challenges of listening', Open Development: Technological, Organizational and Social Innovations Transforming the Developing World. Ottawa.

Waisbord, S. (2008). 'The institutional challenges of participatory communication in international aid', Social Identities, 14 (4), 505-522.

Wheeler, J. (2009). “The Life That We Don't Want': Using Participatory Video in Researching Violence', IDS Bulletin, 40 (3), 10-18.

Wheeler, J. (2011). 'Seeing like Citizen: Participatory Video and Action Research for Citizen Action', in Nishant Shaw and Fieke Jansen (eds.), Digital (Alter)Natives With a Cause? (Book 2 - To Think), 47-60.

White, S. A. (2003). Participatory video: Images that transform and empower. Sage.

Wilkins, K. G., Tufte, T., and Obregon, R. (2014). The handbook of development communication and social change. Chichester, England: Wiley-Blackwell. 